\title{
STUDY OF CERVICAL CYTOLOGY IN MENOPAUSAL WOMEN- IN A MATERNITY AND GENERAL HOSPITAL, HYDERABAD, ANDHRA PRADESH
}

\author{
Bolla Chandrasekhar Reddy ${ }^{1}$, A.R. Rao ${ }^{2}$, K.V. Phani Madhavi ${ }^{3}$, B.P. Ravikumar ${ }^{4}$, Aparna Padala ${ }^{5}$
}

\section{HOW TO CITE THIS ARTICLE:}

Bolla Chandrasekhar Reddy, AR Rao, KV Phani Madhavi, BP Ravikumar, Aparna Padala. "Study of cervical cytology in menopausal women- In a maternity and general hospital, Hyderabad, Andhra Pradesh". Journal of Evolution of Medical and Dental Sciences 2013; Vol2, Issue 36, September 9; Page: 6824-6830.

ABSTRACT: INTRODUCTION: Cytology, today, is widely used for detection of lesions in the cervix. The realization that invasive cancer of the cervix is preceded by recognizable precancerous histological and cytological changes was one of the most basic contributions that aroused greater interest in the possibility of preventing cancer by early cytological detection. OBJECTIVE: The objective of the study is to investigate the incidence of different epithelial abnormalities of the cervix in menopausal and perimenopausal women and compare them with the incidence found in reproductive age group. METHODOLOGY: It is a cross sectional observational study. This study was undertaken to study the cytological features of various lesions in the uterine cervix of different age group patients attending the Gynecological out-patient department of Aparna Maternity and General Hospital, Nagole, Hyderabad from January 2011 to January 2013. INCLUSION CRITERIA: Women of reproductive, perimenopausal (from 40 years) and menopausal age group coming to Out Patient Department for Gynecological checkup. EXCLUSION CRITERIA: Women with following history were excluded from the study: Menstruating / active vaginal bleeding, Inaccessible cervix (due to cervical stenosis or cervix is in flush with vagina), Pregnant women, Hysterectomized women. RESULTS: In this study, satisfactory cervical smear for evaluation were obtained in 953 cases (95.3\%). These smear contained squamous epithelial cells spreaded over more than $10 \%$ of the slide surface and there were accompanied endocervical cell clusters. In 42 cases (4.2\%), the cervical smears were satisfactory, but limited by lack of an endocervical component. In the remaining five patients (0.5\%), the cervical smears were sparsely cellular and obscured by blood and mucinous material. In these five cases, smears were unsatisfactory for evaluation. The study shows the incidence of the clinical lesions in the female genital tract. The incidences of SIL and Frank cancer are, highly associated with the suspicious cervix of about $21 \%$. CONCLUSION: The present study reveals the incidence of different epithelial abnormalities of the cervix in menopausal women compared there with incidence found in women of reproductive age. The present study revealed a high incidence of LSIL and Frank cancer in Menopausal women. Both SIL and cervical carcinoma are associated with multiparity and were commonly observed in women with suspicious cervix and those presenting with bleeding problems. Hence to conclude, cytological screening is mandatory for early detection of SIL, treatment of which would assist in checking in progression of the diseases.

KEYWORDS: Cancer, Parity, Epithelium, Squamous

INTRODUCTION: Cytology, today, is widely used for detection of lesions in the cervix. The realization that, invasive cancer of the cervix is preceded by recognizable precancerous histological and cytological changes was one of the most basic contributions that aroused greater interest in the possibility of preventing cancer by early cytological detection. In 1943, Papanicolaou published his 


\section{ORIGINAL ARTICLE}

monograph. 'Diagnosis of uterine cancer by the vaginal smear'. Papanicolaou's new technique appeared to provide a unique opportunity for detecting cervical cancer at its pre-invasive stage. Confirmation of Papanicolaou's findings by other workers reinforced this view and the first screening clinic was opened in 1945 in Massachusetts (1).

Extended tip wooden Ayre's spatula had more endocervical cells and less often showed absence of diagnostic cells. A new device 'Exact-touch' have been used for obtaining cervical smears. ${ }^{(2)}$ 'Detecta-kits' have been found to be very effective in obtaining adequate samples from the ecto and endocervix.( ${ }^{3}$ ) It has been found that 'Cervitula spatulas' are better than the Aylesbury spatulas, in obtaining adequate cervical smears (4).

Cytological examination of material from the female genital tract is not confined to the diagnosis of precancerous changes in the cervix. Reactive and infective conditions of the cervix, can also be recognized. Cervical smears may include cells exfoliated from the body of the uterus, and even at times, from the fallopian tubes and ovaries, when pathology is present.

The Pap smear is best taken by unroofing the vesicle and taking the smear directly from the material within the vesicle or from the outside edges of the ulcer (5). A study was conducted to find out the prevalence of herpetic cervicitis and opined that cytology may perhaps be more useful in establishing the diagnosis in population studies (6).

Although other sampling methods are now in use for diagnosis of conditions at these remote sites, the cervical smear procedure still dominates the investigation of patients by cytology (7). The present study has been done to for mandatory cytological screening in menopausal women for early detection of SIL, treatment of which would assist in checking the progression of the disease.

OBJECTIVES: To investigate the incidence of different epithelial abnormalities of the cervix in menopausal and perimenopausal women and compare them with the incidence found in reproductive age group.

METHODOLOGY: It is a cross sectional observational study. This study was undertaken to study the cytological features of various lesions in the uterine cervix of different age group patients attending the Gynecological Out Patient department of Aparna Maternity and General Hospital, Nagole, Hyderabad from January 2011 to January 2013.During this period, the patients were selected randomly, all women who were either of reproductive age, perimenopausal and menopausal age group were included in the study group. A total of 1000 cases were studied. INCLUSION CRITERIA: Women of reproductive, perimenopausal (from 40 years) and menopausal age group coming to Out Patient Department for Gynecological checkup. EXCLUSION CRITERIA: Women with following history were excluded from the study: Menstruating / active vaginal bleeding, Inaccessible cervix (due to cervical stenosis or cervix is in flush with vagina), Pregnant women, Hysterectomized.

Procedure of study: Gynecological and obstetrical histories from all patients were recorded with their consent. Information was also recorded regarding marital status, age at first coitus, methods of contraceptive use (if any), and history of multiple sexual partners in the patient or the spouse and prior cytological examination if any. After a through general physical examination, patient was put on the examination table in dorsal position and speculum was introduced into the vagina, exposing the cervix, a cervical scrape was obtained in the each from squamo columnar junction of the cervix 


\section{ORIGINAL ARTICLE}

by using Ayre's spatula by rotating 3600 on cervix (pointed end) and spread the material from both sides of spatula on slide and fixed by the cytofix spray. After fixing the slides were sent to the Pathology Department, where they were stained with Pap stain. A single cytopathologist read all the slides. The cytopathological changes in the cervical epithelium were graded according to the Bethesda system of cervical diagnosis. As a routine, all cases of high grade squamous intraepithelial lesions (HSIL) and frank cancer were histologically confirmed by cervical biopsy.

RESULTS: In this study, satisfactory cervical smear for evaluation were obtained in 953 cases (95.3\%). These smear contained squamous epithelial cells spreaded over more than $10 \%$ of the slide surface and there were accompanied endocervical cell clusters. In 42 cases (4.2\%), the cervical smears were satisfactory, but limited by lack of an endocervical component. In the remaining five patients $(0.5 \%)$, the cervical smears were sparsely cellular and obscured by blood and mucinous material. In these five cases, smears were unsatisfactory for evaluation. (Table: 1)

As shown in the table, the incidence of SIL and Frank cancer in three age groups of women with increasing age after menopause. While SIL rate showed progressive rise with increasing age, malignancies were more frequent in 51-60 yrs. age group i.e., 4.6\%.(Table:2)

In this study the prevalence rate of SIL and Frank invasive carcinoma obtained in the study has been compared with those seen in reproductive age group are shown, the study shows the incidence of SIL was more than double in the menopausal women (11.2\% as against than $3.8 \%)$ than in the reproductive age group women. Similarly malignancy was also more common with menopausal status $(3.2 \%)$ than in reproductive age group of women $(0.8 \%)$. As regards LSIL and HSIL, though there was statistically no significant difference in the HSIL incidence in the two groups, the LSIL rate was very high in menopausal women (9\% as against 2.4\%).(Table:3)

SIL rate was found to be very high in nulliparous women (21.4\%). Both abnormal smears encountered in multiparous were mild dysplasia but the number of women belonging to this group were very small. Otherwise, the incidence rate of SIL and Frank cancer was maximum in number with parity of two or more. (Table: 4 )

The study shows the incidence of the clinical lesions in the female genital tract. The incidences of SIL and Frank cancer are, highly associated with the suspicious cervix of about $21 \%$.( Table: 5)

The study shows the incidence of SIL and Frank cancer in relation to Gynecological Lesions. All the squamous cell atypia are highly associated with in women presenting with bleeding problems (33.3\%). (Table: 6)

DISCUSSION: An attempt is made to optimize the recognition of cervical intra-epithelial carcinoma in-situ (CIS) by the adoption of a standard set of rules derived from a case control study of 50 histologically confirmed used in their study were - chromatin clumping, nucleoli, anisonucleosis, vacuolization, multinucleation, increase in nuclear- cytoplasmic ratio, dyskeratosis and anisocytosis. This standardized cytodiagnosis was found to be relevant to any local diagnosis - specific probability and utility estimates (8). Carcinoma of the uterine cervix is the most prevalent form of cancer. The Preclinical stages of cancer of the cervix are known to last for several years, and they can be detected by simple, reproducible and accurate cytological methods. Since the greatest value of cervical cytology lies in the early detection of the cervical cancer, especially asymptomatic cancer of 


\section{ORIGINAL ARTICLE}

the uterine cervix, its primary application is in the mass screening of asymptomatic women. In this study, smears from the cervix were examined for their diagnostic utility.

Estrogen withdrawal in menopausal women leads to gradual atrophy of the cervical epithelium. The cytomorphological changes obtained in the cervical smears during this period present a bizarre picture which stimulates and may be confused with malignancy. A complete clinical examination of the patient and expertise in the field of cytology are the essential prerequisites for accuracy in diagnostic interpretation of cervical smears in menopausal women. Cervical smears may include cells exfoliated from the body of the uterus, and even at times from the fallopian tubes and ovaries, when pathology is present. Although other sampling methods are now in use for diagnosis of conditions at these remote sites, the cervical smear procedure still dominates the field of investigation of Gynecological patient by cytology.

A study was conducted to evaluate the significance of ASCUS, and observed in the follow-up of these patients that they exhibit a wide spectrum of findings ranging from no pathologic abnormality to frequent SIL and even to invasive carcinoma in rare instances (9)(10).

The inaccuracy of cytologic diagnosis in high -grade squamous intraepithelial lesions was studied and observed that mildly dyskaryotic cells are shed from adjacent areas of low-grade abnormality, and these findings suggest that a lesion has to reach a critical size before it sheds sufficient cells for them to be recognized routinely on a smear (11). It has been observed that, the separation of low-grade squamous intraepithelial lesion into two prognostically different groups, i.e., the cases likely to regress and the cases likely to progress, is not feasible because of its poor cytologic reproducibility and inability to predict differences in biopsy diagnosis (12).

Nearly 500 patients of menopausal, perimenopausal age group and 500 patients of reproductive age group, reporting to Gynecological OPD with various complaints were included in this study. In this study, cervical smears were unsatisfactory for evaluation in 5 cases (0.5\%). In 42 cases (4.2\%), the smears were satisfactory, but limited by absence of endocervical cells. Patient's factors, such as location of the transformation zone, age, previous therapy, may limit to obtain an endocervical sample. In this study, repeat cytological examination was not possible, because all the patients underwent either cervical biopsy a hysterectomy subsequently. In 953 cases (95.3\%), smears were completely satisfactory for evaluation.

In this study, cytological examination of cervical smears reveled squamous Intra epithelial lesions in 56 women (11.2\%) and Frank invasive cancer in 16 cases (3.2\%). The incidence of SIL was more than double in the menopausal women $(11.2 \%$ against than $3.8 \%)$ than that in reproductive age group. Similarly, malignancy was also more common with menopausal status $(3.2 \%)$ than in reproductive age group of women $(0.8 \%)$. In the present study SIL rate was found to be high in nulliparous women (21.4\%) and the incidence of SIL and Frank cancer are highly associated with the suspicious cervix and in women presenting with bleeding problems $(21 \%$ and $33.3 \%$ respectively). The study by Misra JS reveals a higher incidence of LSIL and of Frank cancer in menopausal women than in women in the reproductive age group $(9.1 \%$ and $3.3 \%$ as against $2.1 \%$ and $0.9 \%$ respectively (13). The study by Sadaghi et al found invasive carcinoma to be more common in women older than 50 yrs. Both SIL and Frank cancer were associated with multiparity (14).

CONCLUSION: The present study reveals the incidence of different epithelial abnormalities of the cervix in menopausal women compared there with incidence found in women of reproductive age. 
The present study revealed a high incidence of LSIL and Frank cancer in Menopausal women. Both SIL and cervical carcinoma are associated with multiparity and were commonly observed in women with suspicious cervix and those presenting with bleeding problems. Hence to conclude, cytological screening is mandatory for early detection of SIL, treatment of which would assist in checking in progression of the diseases.

\section{BIBILOGRAPHY:}

1. Coleman DV, Evans DMD. Biopsy pathology and cytology of the cervix. 1st Edn., London, Chapman and Hall 1988.

2. Palo GD. Exact touch - A new device for cervical cytology. Comparison with Ayre's spatula plus cytobrush. Cytopathol 2000; 11:322-325.

3. Misra JS. Comparative evaluation of efficacy of swab sticks with detecta kits for adequate collection of cervical cytology smears. J Cytol 2001; 18:17-19.

4. DoPlessis JM. Aylesbury and cervitula spatulas. A comparative study to assess the adequacy of the cervical smears. Acta Cytol 2001;45:675-678

5. Nuovo GJ. Cytopathology of the lower female genital tract. An integrated approach, USA, Williams and Wilksin. 1994.

6. Shariff S, Thomas JA. Herpetic cervicitis - A histomorphologic study. Indian J Pathol Microbiol 1989; 32:81-91.

7. Winifred G. Diagnostic Cytopathology. 1st Edn., Hongkong, Churchill Livingstone. 1995.

8. DeSomer ML. Standardised model for diagnosing cervical carcinoma in-situ, based on cytologic findings. Acta Cytol 1987; 87:878-881.

9. Anger M, ASCUS - A cyto-histologic study of 52 cases. Acta Cytol 1997; 41:1671-1675.

10. Lousebsakul V. Clinical impact of ASCUS - A cytohistologic comparison. Acta Cytol 2000;44:23-30

11. Lyall H, Duncan ID; Inaccuracy of cytologic diagnosis in HSILs. Acta Cytol 1995; 39:50-54.

12. Lee RK. Koilocytotic atypia in Papanicolaou smears. Reproducibility and biopsy correlations. Cancer Cytopathol 1997; 81:10-15.

13. Misra JS, Pandey S. Cervical cytology in menopausal women. J Obstet Gynecol Ind 2003; 53(5):468-472.

14. Sadaghi SB, Sadaghi A, Robboy SL. Prevalence of dysplasia and cancer of cervix in a nationwide planned parenthood population. Cancer 1988; 61:2359-61.

\begin{tabular}{|c|c|c|}
\hline Adequacy of the specimen & No. of cases & Percentage \\
\hline Satisfactory for evaluation & 953 & $95.3 \%$ \\
\hline $\begin{array}{l}\text { Satisfactory for evaluation, } \\
\text { but limited by lack of } \\
\text { endocervical cell component }\end{array}$ & 42 & $4.2 \%$ \\
\hline Unsatisfactory smears & 5 & $0.5 \%$ \\
\hline
\end{tabular}




\begin{tabular}{|c|c|c|c|c|c|}
\hline \multirow{2}{*}{$\begin{array}{c}\text { Age } \\
\text { group }\end{array}$} & \multirow{2}{*}{$\begin{array}{l}\text { No. of } \\
\text { cases }\end{array}$} & \multicolumn{3}{|c|}{ SIL } & \multirow[b]{2}{*}{$\begin{array}{l}\text { Frank } \\
\text { cancer }\end{array}$} \\
\hline & & LSIL & HSIL & $\begin{array}{c}\text { Over all } \\
\text { prevalence rate }\end{array}$ & \\
\hline$<40$ yrs & 500 & $12(4.7 \%)$ & $19(5.7 \%)$ & $31(12.1 \%)$ & $4(1.2 \%)$ \\
\hline $40-50$ yrs & 252 & $20(7.9 \%)$ & $5(1.5 \%)$ & $25(9.8 \%)$ & $5(1.5 \%)$ \\
\hline $51-60$ yrs & 172 & $16(9.3 \%)$ & $9(5.2 \%)$ & $25(14 \%)$ & $8(4.6 \%)$ \\
\hline $61-70$ yrs & 76 & $7(9.2 \%)$ & $3(3.9 \%)$ & $10(13.1 \%)$ & $2(2.6 \%)$ \\
\hline
\end{tabular}

Table II : Relation between Epithelial Abnormalities and Age

$\chi 2=24.438, p=0.000$

\begin{tabular}{|c|c|c|c|c|}
\hline Epithelial abnormalities & $\begin{array}{c}\text { Perimenopausal and } \\
\text { Menopausal women }\end{array}$ & $\begin{array}{c}\text { Women of } \\
\text { reproductive } \\
\text { age group }\end{array}$ & $\mathbf{Z}$ & $\mathbf{P}$ \\
\hline SIL & $56(11.2 \%)$ & $19(3.8 \%)$ & 4.322 & 0.000 \\
\hline LSIL & $45(9 \%)$ & $12(2.4 \%)$ & 4.365 & 0.000 \\
\hline HISL & $11(2.2 \%)$ & $6(1.2 \%)$ & 0.978 & 0.328 \\
\hline Moderate dysplasia & $11(2.2 \%)$ & $4(0.8 \%)$ & 1.561 & 0.119 \\
\hline Severe dysplasia & $0(0 \%)$ & $2(0.4 \%)$ & NA & NA \\
\hline Frank invasive carcinoma & $16(3.2 \%)$ & $4(0.8 \%)$ & 2.845 & 0.013 \\
\hline
\end{tabular}

Table III: Comparison of Incidence of sil, lsil, hsil, and Frank

Cancer in Menopausal and Reproductive age groups of women

\begin{tabular}{|c|c|c|c|c|c|}
\hline \multirow{2}{*}{ Parity } & \multirow{2}{*}{$\begin{array}{l}\text { No. of } \\
\text { cases }\end{array}$} & \multicolumn{3}{|c|}{ SIL } & \multirow{2}{*}{ Frank cancer } \\
\hline & & LSIL & HSIL & Over all prevalence rate & \\
\hline 0 & 42 & $9(21.4 \%)$ & $0(0 \%)$ & $9(21.4 \%)$ & $0(0 \%)$ \\
\hline 1 & 136 & $0(0 \%)$ & $0(0 \%)$ & $0(0 \%)$ & $0(0 \%)$ \\
\hline 2 & 354 & $28(7.9 \%)$ & $0(0 \%)$ & $28(7.9 \%)$ & $6(1.6 \%)$ \\
\hline$>3$ & 468 & $36(7.6 \%)$ & $13(2.7 \%)$ & $49(10.4 \%)$ & $17(3.6 \%)$ \\
\hline
\end{tabular}

$\chi 2=16.620 \mathrm{p}=0.002$

\begin{tabular}{|c|c|c|c|c|c|}
\hline \multirow[b]{2}{*}{ lesions } & \multirow[b]{2}{*}{$\begin{array}{l}\text { No. of } \\
\text { cases }\end{array}$} & \multicolumn{3}{|c|}{ SIL } & \multirow[b]{2}{*}{ Frank cancer } \\
\hline & & LSIL & HSIL & $\begin{array}{c}\text { Over all } \\
\text { prevalence rate }\end{array}$ & \\
\hline Erosion Cervix & 42 & $9(21.4 \%)$ & $0(0 \%)$ & $9(21.4 \%)$ & $0(0 \%)$ \\
\hline Hypertrophied Cervix & 136 & $0(0 \%)$ & $0(0 \%)$ & $0(0 \%)$ & $0(0 \%)$ \\
\hline Suspicious Cervix & 354 & $28(7.9 \%)$ & $0(0 \%)$ & $28(7.9 \%)$ & $6(1.6 \%)$ \\
\hline Senile Vaginitis & 468 & $36(7.6 \%)$ & $13(2.7 \%)$ & $49(10.4 \%)$ & $17(3.6 \%)$ \\
\hline
\end{tabular}

$\chi 2=12.044 \mathrm{p}=0.017$ 
ORIGINAL ARTICLE

\begin{tabular}{|c|c|c|c|c|c|}
\hline \multirow[b]{2}{*}{ Symptoms } & \multirow[b]{2}{*}{$\begin{array}{l}\text { No. of } \\
\text { cases }\end{array}$} & \multicolumn{3}{|c|}{ SIL } & \multirow[b]{2}{*}{$\begin{array}{l}\text { Frank } \\
\text { cancer }\end{array}$} \\
\hline & & LSIL & HSIL & $\begin{array}{c}\text { Over all } \\
\text { Prevalence rate }\end{array}$ & \\
\hline $\begin{array}{l}\text { Post menopausal } \\
\text { bleeding }\end{array}$ & 45 & $11(24.4 \%)$ & $4(8.8 \%)$ & $15(33.3 \%)$ & $7(15.5)$ \\
\hline Leucorrhea & 296 & $42(14.2 \%)$ & $4(1.3 \%)$ & $46(15.5 \%)$ & $5(1.7 \%)$ \\
\hline $\begin{array}{c}\text { Pain in lower } \\
\text { abdomen }\end{array}$ & 103 & $12(11.6 \%)$ & $0(0 \%)$ & $12(11.6 \%)$ & $0(0 \%)$ \\
\hline
\end{tabular}

$\chi 2=46.581 \mathrm{p}=0.000$

\section{AUTHORS:}

1. Bolla Chandrasekhar Reddy

2. A.R. Rao

3. K.V. Phani Madhavi

4. B.P. Ravikumar

5. Aparna Padala

\section{PARTICULARS OF CONTRIBUTORS:}

1. Assistant Professor, Department of Community Medicine, Mamata Medical college, Khammam.

2. Assistant Professor, Department of Community Medicine, Apollo Medical College. Hyderabad.

3. Assistant Professor, Department of Community Medicine, Mamata Medical college, Khammam.

4. Assistant Professor, Department of Community Medicine, Mamata Medical college, Khammam.
5. Practitioner, Aparna Maternity and General Hospital, Nagole, Hyderabad, Andhrapradesh, India.

\section{NAME ADDRESS EMAIL ID OF THE CORRESPONDING AUTHOR:}

Dr. Bolla Chandrasekhar Reddy, \# 104, Sairanga Asian Residency, Beside Sairanga Theatre, Miyapur, Hyderabad - 500049. Email -drchandureddi@gmail.com

Date of Submission: 19/08/2013. Date of Peer Review: 20/08/2013. Date of Acceptance: 27/08/2013. Date of Publishing: 03/09/2013 